\title{
X-Chromosome Inactivation and Mutation Pattern in the Bruton's Tyrosine Kinase Gene in Patients with $\mathrm{X}$-linked Agammaglobulinemia
}

\author{
Viviana Moschese ${ }^{1,2}$, Paola Orlandi ${ }^{1,2}$, Alessandro Plebani $^{3}$, \\ Konstantinos Arvanitidis ${ }^{4}$, Maurilia Fiorini ${ }^{3}$, Matthaios Speletas ${ }^{5}$, \\ Patrizia Mella ${ }^{3}$, Kostas Ritis ${ }^{5}$, Paschalis Sideras", Andrea Finocchi ${ }^{2}$, \\ Susanna Livadiotti ${ }^{2}$, Paolo Rossi ${ }^{1,2}$, and in collaboration with the Italian XLA \\ Collaborative Group \\ ${ }^{1}$ Chair of Pediatrics, University of Rome Tor Vergata, School of Medicine, Rome, Italy \\ ${ }^{2}$ Division of Immunology and Infectious Diseases, Children's Hospital Bambino \\ Gesù, Rome, Italy \\ ${ }^{3}$ Department of Pediatrics, University of Brescia, Italy \\ ${ }^{4}$ Department of Applied Cell and Molecular Biology, Umea University, Sweden \\ ${ }^{5}$ Department of Hematology, Demokritus University of Thrace, Alexandroupolis, Greece \\ Communicated by H. Wigzell. Accepted November 9, 1999.
}

\begin{abstract}
Background: The diagnosis of X-linked agammaglobulinemia (XLA) is not always clearcut. Not all XLA conform to the classic phenotype and less than $50 \%$ of affected boys have a family history of immunodeficiency. Mutations in the gene for Bruton's tyrosine kinase (BTK) are responsible for the majority of agammaglobulinemia cases. However, a certain proportion of patients may have mutations involving other genes, although they show with an XLA phenotype. We performed BTK gene mutation analysis in 37 males with presumed XLA and analyzed the pattern of X-chromosome inactivation (XCI) in 31 mothers to evaluate the relevance of these approaches to diagnosis and genetic counseling. Materials and Methods: Twenty affected males with a sporadic occurrence and 17 familial cases belonging to nine families were enrolled within the framework of the Italian Multicenter Clinical Study on XLA. We used non-isotopic RNase cleavage assay (NIRCA), followed by cDNA sequence determination to screen for BTK mutations and X-chromosome inactivation analysis for carrier detection.
\end{abstract}

Results: Using the cDNA-based approach, the identification of BTK gene abnormalities confirmed the clinical diagnosis of XLA in 31 of 37 affected infants. Missense was the most frequent mutational event and the kinase domain was mostly involved. In addition, nine novel mutations were identified. In sporadic cases, BTK gene abnormalities were identified in 9 out of 10 patients whose mothers had a nonrandom pattern of XCI and in 5 out of 6 patients whose mother had a random pattern of XCI. With the exception of one family, all patients with a familial occurrence and born to mothers with a nonrandom pattern of XCI had mutations of the BTK gene.

Conclusions: Our findings indicate that in sporadic cases BTK gene sequencing is the only reliable tool for a definitive diagnosis of XLA and support $\mathrm{XCI}$ as the first diagnostic tool in the mothers of affected males in multiple generations. Furthermore, our molecular analysis confirms that $10-20 \%$ of BTK-unaltered patients have disorders caused by defects in other genes.
Address correspondence and reprint requests to: Dr. Viviana Moschese, Department of Pediatrics, University of Rome Tor Vergata, Division of Immunology and Infectious Diseases, Children's Hospital Bambino Gesù, Piazza S. Onofrio, 4, 00165 Rome, Italy. Phone: 06-68592508; Fax: 06-68592508; E-mail: vivimos@tin.it

\section{Introduction}

$\mathrm{X}$-linked agammaglobulinemia (XLA) is a fully penetrant, $\mathrm{X}$-linked, recessive immunodeficiency caused by a block in B-cell differentiation, which results in a selective defect of the 
humoral immune response $(1,2)$. Affected males develop recurrent and severe bacterial infections and are at risk of disseminated infections with enteroviruses $(1,2)$. Peripheral B cells of these patients are usually $1-2 \%$ of normal and they are unable to make functional antibody responses; consequently, serum immunoglobulins are profoundly decreased. The normal number of pro-B cells and the marked reduction of pre-B cells suggests impaired cellular proliferation or increased cell death during early B-cell development. Using linkage analysis, the XLA gene was first mapped on the long arm of the human $\mathrm{X}$-chromosome in the region of Xq21.3-22 (3,4). In early 1993, the gene responsible for XLA was identified as a cytoplasmic tyrosine kinase, named Bruton's tyrosine kinase (BTK) $(5,6)$.

The BTK gene comprises 19 exons encompassing approximately $37 \mathrm{~kb}$ of genomic DNA (7). The first exon and $30 \mathrm{bp}$ of the second exon constitute the $5^{\prime}$ untranslated region of the BTK mRNA. The 659-amino acid-encoded protein shows sequence identity to an emerging family of Src-related tyrosine kinases, including Itk, Tec, DrSrc28C and Bmx, characterized by the presence of a pleckstrin homology $(\mathrm{PH})$ domain at the amino terminus (BTK residues 1-137), followed by a cysteine-rich and a proline-rich region representing the Tec homology (TH) domain (BTK residues 138-214) $(8,9)$. The Src homology domains 3 (SH3) and 2 (SH2) and the kinase catalytic domain ( $\mathrm{SH} 1)$ follow in tandem at the carboxy terminus (BTK residues $215-279 ; 280-376$ and 377-659, respectively) (9).

Both the maintenance of peripheral B-cell numbers and their response to $\mathrm{B}$-cell antigen receptor (BCR) crosslinking depend on BTK (10). BTK integrates signals from multiple cell surface receptors, including BCR and Gprotein coupled receptors (10-12). These BTKdependent signals control B-cell proliferation and survival by mediating $\mathrm{Ca}^{+}$flux, activating JNK and p38, and inducing cell cycle regulatory genes (10).

Current data suggest that the $\mathrm{PH}$ domain is likely to be involved in the intracellular translocation of BTK and, perhaps, in binding to critical substrates, since mutations of this molecule inactivate the BTK pathway in cell signaling by reducing its affinity for inositol phosphates $(13,14)$. Heterotrimeric G protein $\mathrm{G}_{\mathrm{q}} \alpha$ binds directly to a region composed of a $\mathrm{TH}$ and a SH3 domain (11). Mutations in this
BTK region disrupt the TH-SH3 intramolecular interaction altering its ability to bind $\mathrm{G}_{\mathrm{q}} \alpha$ and eliminating BTK activation (11). Activation of BTK involves recruitment to the cell membrane through interaction between the BTK PH domain and phosphoinositide 3-kinase (PI3K) lipid products $(15,16)$. Recently, it was shown that mice with a targeted gene disruption of the p $85 \alpha$ subunit of PI3K show a phenotype similar to xid mice $(17,18)$, thus, further demonstrating that PI3K and BTK are functionally linked along B-cell differentiation. Although the XLA and the mouse (xid) phenotypes indicate that BTK is essential for normal immune responsiveness, the function of this kinase and of each single domain needs to be further clarified (2).

The frequency of XLA has been estimated to be $1: 200,000$ live births (19). Making the diagnosis of XLA is not always straightforward. Atypical cases are common and $30-50 \%$ of boys with the clinical and laboratory features of XLA (XLA phenotype) have no family history of disease (20). Accurate diagnosis and genetic counseling are further complicated by autosomal recessive forms of this disorder that result in a XLA phenotype (21-26). Carrier detection, by analysis of $\mathrm{X}$-chromosome inactivation patterns in B-cells, can be an important adjunct to confirm the diagnosis of XLA in atypical or sporadic cases (26-29). However, a random pattern does not, per se, exclude the possibility of a de novo mutation in the maternal germ line. Molecular analysis of BTK mutations has proven a more accurate means of diagnosis of affected individuals. In particular, the use of genomic DNA rather than cDNA would have the advantage of identifying mutations in regulatory sites, although it can be time-consuming and expensive. In the current study, we performed BTK gene mutation analysis of the cDNA of 37 males with an XLA phenotype belonging to 29 families and analyzed the pattern of Xchromosome inactivation in 31 mothers, with the ultimate goal of evaluating the power of these diagnostic tools for providing a definitive molecular diagnosis of XLA.

\section{Materials and Methods}

\section{Patients}

Thirty-seven male patients with reduced serum immunoglobulin levels, absent to low 
$(<1 \%)$ levels of circulating B cells and an XLA phenotype were enrolled into the Italian Multicenter Clinical Study on XLA. Family history was negative for XLA in 20 (sporadic cases) and positive in the remaining 17 (familial cases). The patients of the latter group belonged to nine families; four families had affected males in multiple generations and the remaining five had affected males only in the same sibship. Serum immunoglobulin levels were determined by nephelometric technique and the percentages of circulating $T$ and B lymphocytes were evaluated by FACS analysis using anti-CD3,-CD4,-CD8, CD20/19 monoclonal antibodies.

BTK gene sequence analysis of 35 patients was performed at the laboratory of Immunology, University of Rome Tor Vergata, Rome, Italy. The remaining two patients, $\mathrm{n}^{\circ} 2$ and 16 were only investigated by non-isotopic RNase cleavage assay (NIRCA), since their samples were not available for BTK gene sequencing. Relationships within the members were unknown at the time of genetic analysis. The $\mathrm{X}$-chromosome inactivation pattern was investigated at the laboratory of Immunology, University of Brescia, Brescia, Italy, on B cells of 31 mothers from 29 families.

\section{Analysis of BTK Mutation}

CDNA PREPARATION. RNA for polymerase chain reaction (PCR) amplification was prepared directly from uncultured patients' peripheral blood mononuclear cells (PBMC) according to common procedures (30). Briefly, PBMC were isolated using Ficoll density centrifugation and mononuclear cells were pelletted. Total RNA was extracted by TRIzol ${ }^{\circledR}$ (Gibco-BRL/Life Technologies, Gaithersburg, MD) according to manufacturer's instructions and suspended in $50 \mu \mathrm{l}$ of TE buffer. cDNA synthesis was performed using Promega (M-MLV) reverse trancriptase according to manufacturer's instructions.

PCR AMPLIFICATION. CDNA samples were amplified by PCR as previously described $(30,31)$. Briefly, BTK cDNA was divided into four fragments, called PH, TS, SK and KIN, that were amplified by nested PCR. The sequences of T7 and SP6 RNA promoters constituted the $5^{\prime}$ end of sense and antisense nested primers, respectively. After a first denaturation at $94^{\circ} \mathrm{C}$ for $2 \mathrm{~min}$, outer PCR cycling conditions were $94^{\circ} \mathrm{C}$ for $30 \mathrm{sec}$, $55^{\circ} \mathrm{C}$ for $45 \mathrm{sec}$ and $72^{\circ} \mathrm{C}$ for $90 \mathrm{sec}$, repeated 30 times, followed by a final extension at $72^{\circ} \mathrm{C}$ for $5 \mathrm{~min}$. An annealing temperature of $57^{\circ} \mathrm{C}$ for $60 \mathrm{sec}$ was used for the SK fragment. Inner PCR conditions were the following: $94^{\circ} \mathrm{C}$ for $30 \mathrm{sec}$, $55^{\circ} \mathrm{C}$ for $45 \mathrm{sec}$ and $72^{\circ} \mathrm{C}$ for $90 \mathrm{sec}$, repeated for 25 cycles for TS and SK fragments and for 20 cycles for PH and KIN fragments.

NIRCA (NON ISOTOPIC RNASE CLEAVAGE ASSAY). This method was based on previously described protocol $(30,31)$. Briefly, a sense RNA product generated in vitro from wild-type control, using appropriate RNA polymerase, was hybridized separately with the antisense RNA strand generated from the same template (as wild-type control) and XLA patient templates. As a procedure control, similar hybridization was performed using the anstisense RNA strand of the wild-type sample with the patient's sense strand. Sense and antisense RNA strands from each patient were also hybridized to each other as a second unmutated control. 1-4 $\mu$ l of inner PCR product was used as template for $10 \mu \mathrm{l}$ trancription reaction, performed at $37^{\circ} \mathrm{C}$ for $90 \mathrm{~min}$. Hybridation reactions were carried out according to manufacturer instructions. Any mismatches in RNA-RNA hybrids were revealed by RNase digestion and separated by $1.5 \%$ agarose gel electrophoresis.

SEQUENCING. The mutated fragment was amplified with Pfu polymerase and cloned into PCRScript Amp Cloning Kit (Stratagene, Heidelberg, Germany). Positive clones were then amplified for direct solid-phase DNA sequencing according to standard procedures (32). Briefly, the amplified product was purified by immobilization on mag-netic beads (Dynabeads M280streptavidin; Dynal AS, Oslo, Norway) and, subsequently, denatured to obtain single-stranded DNA. Fluorescent M13 universal forward and reverse primers were used for the sequencing of both DNA strands (Autoread Sequencing Kit, Pharmacia LKB, Uppsala, Sweden) and the sequence fragments generated were then loaded on a $6 \%$ polyacrylamide gel in an automated laser fluorescent (A.L.F.) sequencing apparatus (Pharmacia LKB).

\section{$X$-Chromosome Inactivation}

Cell separation and PCR conditions for the carrier assay were described previously (29). Briefly, B lymphocytes were isolated from the 
mononuclear cell fraction of $20 \mathrm{ml}$ of blood by using anti-CD19 immunomagnetic beads (Dynal). Purity of the $\mathrm{CD} 19^{+}$population was confirmed by flow cytometry using the B-cellspecific marker CD20; all B-cell populations used for DNA analysis were $>95 \% \mathrm{CD}^{+} 0^{+}$. Moreover, DNA was also extracted from nonB-mononuclear cells (i.e., the negative fraction following selection with anti-CD19-coated immunomagnetic beads) and granulocytes. A crude DNA extract was prepared from each of the $\mathrm{B}$ cells, non-B lymphocytes, and granulocytes fractions. DNA samples were digested with $R s a \mathrm{I}$ and then divided into two aliquots, one of which was further digested with the methylation sensitive enzyme HpaII. The DNA samples were then used as template for PCR across the first exon of the human androgen receptor (HUMARA) gene that contains a $(\mathrm{CAG})_{\mathrm{n}}$ repeat, allowing the distinction between the two X-chromosome alleles in $>90 \%$ of the females. Amplification products were run onto a $12 \%$ acrylamide-bisacrylamide, $10 \%$ urea gel electrophoresis.

The assay was considered informative when two alleles appeared in the samples digested with RsaI alone. In informative females, for each cell population, a random pattern of $\mathrm{X}$-chromosome inactivation was defined by the persistence of both HUMARA alleles in the HpaII-digested DNA sample. In contrast, a carrier status of XLA was implied when only one of the two HUMARA alleles could be revealed in the HpaII-digested DNA sample extracted from B cells; whereas, a random pattern of $\mathrm{X}$-chromosome inactivation was present in the non-B and granulocytes fractions from the same subject. Finally, the demonstration of an obvious predominance of one of the two HUMARA alleles in all of the HpaII-digested DNA samples (i.e. from B, non-B cells, and granulocytes) obtained from the same woman was defined as skewed $\mathrm{X}$-chromosome inactivation.

\section{Results}

We used the NIRCA assay followed by DNA sequence determination to screen for BTK mutations in 37 males with an XLA phenotype belonging to 29 families. Twenty out of 37 were sporadic cases, while the remaining 17 belonged to nine families with multiple cases of agammaglobulinemia in males. In particular, five families had affected males only in the same sibship (one pair of brothers per family, accounting for 10 of the 17 patients); whereas, four families had affected males in multiple generations and accounted for the remaining seven familial cases (one pair of brothers and one maternal uncle in one family, one nephew and one maternal uncle in another family, and one patient for each of the two remaining families).

Using our cDNA-based approach, the identification of BTK gene abnormalities confirmed the clinical diagnosis of XLA in 31 of 37 affected infants. All mutations were unique to each family, since no distinct mutation was detected in more than one family. All five domains were involved, but were more common in the kinase domain. Five mutations occurred in the PH domain, three in the TH domain, one in $\mathrm{SH} 2$ and two in the $\mathrm{SH} 3$ domains; whereas, 20 involved the kinase domain. As shown in Table 1, in 29 of these 31 genotypically identified XLA patients, sequence analysis demonstrated 18 missense, four non-sense, five frameshift, one in-frame insertion of a stop codon and one splice site defect. Missense mutations were not detected in $\mathrm{SH} 2$ and $\mathrm{TH}$ domains. The majority of them were located in the kinase domain. In our cohorts, mutations in the kinase domain were most represented: 11 unique missense mutations, two deletions causing a frameshift, one in-frame insertion and one splice site defect. The following mutations could be found in the PH domain: two missense, one non-sense and a deletion. Missense mutations in the $\mathrm{PH}$ domain affected residues $\mathrm{R} 28$ and Y39, which were likely to be involved in membrane anchoring (33). Also, mutation $\mathrm{R} 28 \mathrm{H}$ has been frequently observed in XLA patients and R28C found in xid mice (33-35). Two frameshift mutations caused by one base pair insertion were found in the $\mathrm{TH}$ domain. One non-sense mutation was found in the SH2 domain; whereas, one missense and one non-sense mutation were identified in the SH3 domain. No BTK mutations were found in six male patients with agammaglobulinemia; two were sporadic cases and four represented two pairs of siblings.

BTK gene mutations were identified in 7 of 9 pedigrees with familial occurrence of agammaglobulinemia. Identical BTK mutations and comparable clinical and laboratory phenotype within the members of the same family were observed. The distribution of the mutations was located on the kinase domain, except for one family, where a $\mathrm{PH}$ domain 
Table 1. BTK gene mutations detected in 29 XLA patients

\begin{tabular}{|c|c|c|c|c|c|}
\hline Patient & $\begin{array}{l}\text { Protein } \\
\text { Domain }^{*}\end{array}$ & Exon & $\begin{array}{c}\text { Nucleotide } \\
\text { Change }\end{array}$ & $\begin{array}{l}\text { Involved } \\
\text { Codon }\end{array}$ & Effect on Coding Sequence \\
\hline BTK 14 & PH & 2 & AAA/TAA 187 & K19 & Lys $\rightarrow$ Stop \\
\hline BTK 26 & PH & 2 & CGC/CAC 215 & $\mathrm{R} 28$ & Arg $\rightarrow$ His \\
\hline BTK 27 & $\mathrm{PH}$ & 2 & CGC/CAC 215 & $\mathrm{R} 28$ & Arg $\rightarrow$ His \\
\hline BTK 10 & $\mathrm{PH}$ & 2 & TAC/TCC 248 & Y39 & Tyr $\rightarrow$ Ser \\
\hline BTK 34 & $\mathrm{PH}$ & 6 & $534 \mathrm{C}$ del & R 134 & Frameshift \\
\hline ВТK 19 & $\mathrm{TH}$ & 7 & 654-655 $\mathrm{T}$ ins & L175 & Frameshift \\
\hline BTK 39 & TH & 7 & $688 \mathrm{~A}$ ins & K 185 & Frameshift \\
\hline BTK 40 & $\mathrm{TH}$ & 8 & CGA/TGA 895 & $\mathrm{R} 255$ & Arg $\rightarrow$ Stop \\
\hline BTK 18 & SH2 & 11 & CAA/TAA 1109 & Q293 & Gln $\rightarrow$ Stop \\
\hline BTK 25 & SH3 & 9 & CAG/TAG 911 & Q260 & Gln $\rightarrow$ Stop \\
\hline BTK 4 & KIN & 15 & 1599-1602 GCGC del & R490/H491 & Frameshift \\
\hline BTK 51 & KIN & 15 & TGT/TAT 1649 & C506Y & Cys $\rightarrow$ Tyr \\
\hline BTK 61 & KIN & 15 & TGT/TAT 1649 & C506Y & Cys $\rightarrow$ Tyr \\
\hline BTK 35 & KIN & 15 & CTG/CCG 1667 & L512 & Leu $\rightarrow$ Pro \\
\hline BTK 36 & KIN & 15 & CTG/CCG 1667 & L512 & Leu $\rightarrow$ Pro \\
\hline BTK 37 & KIN & 15 & CTG/CAG 1667 & L512 & $\mathrm{Leu} \rightarrow \mathrm{Gln}$ \\
\hline BTK 22 & KIN & - & $\mathrm{G} / \mathrm{T}$ & $(522)$ & Splice-donor defect $(+1)$ \\
\hline BTK 28 & KIN & 16 & CGA/CCA 1706 & R525 & Arg $\rightarrow$ Pro \\
\hline BTK 52 & KIN & 16 & 1712-1713 TG del & $\mathrm{C} 527$ & Frameshift \\
\hline BTK 49 & KIN & 16 & AGG/GGG1763 & R544 & Arg $\rightarrow$ Gly \\
\hline BTK 50 & KIN & 16 & AGG/GGG1763 & R544 & Arg $\rightarrow$ Gly \\
\hline BTK 38 & KIN & 17 & TGT/TAT 1866 & S578 & Ser $\rightarrow$ Tyr \\
\hline BTK 29 & KIN & 18 & GAA/AAA 1897 & E589 & Glu $\rightarrow$ Lys \\
\hline BTK 5 & KIN & 18 & GGG/CGG 1912 & G594 & Gly $\rightarrow$ Arg \\
\hline BTK 12 & KIN & 18 & GGG/GAG 1913 & G594 & Gly $\rightarrow$ Glu \\
\hline BTK 13 & KIN & 18 & GGG/GAG 1913 & G594 & Gly $\rightarrow$ Glu \\
\hline BTK 33 & KIN & 18 & GGG/GAG 1913 & G594 & Gly $\rightarrow$ Glu \\
\hline BTK 7 & KIN & 18 & 2037-2038 TTTTAG ins & $635 F B 636$ & In frame insertion \\
\hline BTK 8 & KIN & 19 & CGT/TGT 2053 & R641 & Arg $\rightarrow$ Cys \\
\hline
\end{tabular}

*KIN = kinase domain; $\mathrm{PH}=$ pleckstrin homology domain; $\mathrm{SH}=$ Src homology domain; $\mathrm{TH}=$ Tec homology domain

mutation caused the disease. Mutations were recurrent, but two novel mutations in the kinase domain, L512P and R544G, which were singularly found in one pair of siblings (our personal data, manuscript in publication). Two families, each consisting of two brothers, showed no mutations in BTK. In one of these families, both brothers (patients 20 and 21) had suffered from recurrent upper and lower respiratory infections and showed a mild hypogammaglobulinemia. One of them (patient 21) was sometimes reported to have B-cell numbers ranging from 2 to $3.5 \%$; whereas, the other had lower B-cell values. In the other family (patients 23 and 24), a classical clinical and immunological XLA phenotype was instead observed in both brothers at the time of enrollment.

Among males with sporadic occurrence of agammaglobulinemia, BTK gene mutations were identified in 18 of 20 cases. Seven novel mutations were identified: four missense, one deletion, one non-sense and one in-frame insertion (our personal data, manuscript in publication). So far, only two in-frame insertions, one in the $\mathrm{PH}$ domain and the other one in the 
kinase domain were reported to the BTKbase by Vihinen et al. (http://www.uta.fi/imt/ bioinfo) (36). As reported elsewhere $(33,36$, 37), no correlation between genotype and phenotype were found in our XLA patients. However, the lowest immunoglobulin G (IgG) values, together with an undetectable level of B lymphocytes, was found in the patient with the uncommon in-frame insertion at the kinase domain.

To perform carrier detection, the pattern of $\mathrm{X}$-chromosome inactivation was studied in the B-cells from the mothers of 20 sporadic cases and from the 11 mothers of 17 familial cases. In the mothers of sporadic cases, the pattern of $\mathrm{X}$-chromosome inactivation was non-random in 10, random in six, highly skewed in one, and non-informative in three. As shown in Table 2, BTK gene abnormalities were identified in 9 out of 10 patients whose mothers had a nonrandom pattern of $\mathrm{X}$-chromosome inactivation, in all three patients whose mothers had a noninformative pattern, in 5 of 6 patients whose mothers had a random pattern and in the one whose mother showed a skewed pattern. On the whole, BTK gene analysis allowed diagnosis of XLA in 18 out of 20 sporadic cases. Interestingly, no BTK mutations were found in one patient whose mother had a random pattern of $\mathrm{X}$-chromosome inactivation, possibly indicating an autosomal recessive form of agammaglobulinemia. In contrast, BTK gene mutations were found in 5 of 6 patients whose mothers had a random pattern of $\mathrm{X}$-chromosome inactivation, supporting the hypothesis of de novo mutation or of germinal mosaicism. In the 11 mothers of 17 familial cases, the $\mathrm{X}$-chromosome inactivation pattern was non-random in nine and highly skewed in the remaining two. The relationship between the maternal $\mathrm{X}$-chromosome inactivation pattern and BTK gene abnormali- ties in the familial cases is shown in Table 3. With the exception of family two, all patients born to mothers with a non-random pattern of $\mathrm{X}$-chromosome inactivation had mutations of the BTK gene. Of the two sib pairs, each of whom were born to the two mothers with a skewed inactivation pattern, a BTK gene mutation was found in one pair.

\section{Discussion}

In the framework of the Italian XLA Collaborative Study, which has thus far enrolled about 70 patients, we present here the data of the first analysis of the BTK gene from 37 members of 29 families with an XLA phenotype and the pattern of $\mathrm{X}$-chromosome inactivation of 31 mothers. Among the 20 sporadic cases, BTK mutations were identified in 18 , indicating that gene mutations can be found in $\mathbf{9 0 \%}$ of males with sporadic immunodeficiency characterized by early onset of infections, hypogammaglobulinemia and circulating B-cell numbers below $1 \%$. Mutations were found in 9 of the 10 patients whose mothers had a non-random pattern of $\mathrm{X}$-chromosome inactivation, in all three with a non-informative pattern, in the only one with a skewed pattern, and in 5 of the 6 with a random pattern. This suggests that, in males with a sporadic occurrence of an XLA phenotype, molecular diagnosis with BTK gene sequencing is an essential tool for defining XLA. No BTK mutation was found in one patient whose mother had a non-random X-chromosome inactivation pattern, suggesting that this patient may have a mutation at a site not screened by NIRCA analysis, or a substantial mutation that did not cause an altered migration, or, alternatively, that other gene(s) on the $\mathrm{X}$-chromosome can be responsible for his XLA

Table 2. X-chromosome inactivation (XCI) in 20 mothers of infants with sporadic XLA in relation to BTK gene analysis

\begin{tabular}{llcc}
\hline Pattern of XCI & & $\begin{array}{c}\text { No BTK } \\
\text { Mutations (2/20 }=\mathbf{1 0} \%)\end{array}$ & $\begin{array}{c}\text { Presence of BTK } \\
\text { Mutations }(\mathbf{1 8} / \mathbf{2 0}=\mathbf{9 0} \%)\end{array}$ \\
\hline Non-random & $\mathrm{n}^{\circ} 10$ & 1 & 9 \\
Random & $\mathrm{n}^{\circ} 6$ & 1 & 5 \\
Skewed & $\mathrm{n}^{\circ} \mathbf{n}$ & - & 1 \\
Non-informative & $\mathrm{n}^{\circ} 3$ & - & 3 \\
\end{tabular}


Table 3. $\mathrm{X}$-Chromosome inactivation (XCI) in 11 mothers of infants with familial XLA in relation to $B$ TK gene analysis

\begin{tabular}{|c|c|c|}
\hline Family & XCI & BTK Mutations \\
\hline 1. $M 20-21^{*}$ & SK & \\
\hline 20 & & - \\
\hline 21 & & - \\
\hline 2. M23-24* & NR & \\
\hline 23 & & - \\
\hline 24 & & - \\
\hline 3. $\mathrm{MO2}^{\circ}$ & NR & \\
\hline 02 & & + \\
\hline 4. $\mathrm{M}^{\circ} 5^{\circ}$ & NR & \\
\hline 05 & & + \\
\hline 5. $M 12-13^{\circ}$ & NR & \\
\hline 12 & & + \\
\hline 13 & & + \\
\hline 6. $\mathrm{M} 33^{\circ}$ & NR & \\
\hline 33 & & + \\
\hline 7. $M 35-36^{*}$ & NR & \\
\hline 35 & & + \\
\hline 36 & & + \\
\hline 8. $M 49-50^{*}$ & SK & \\
\hline 49 & & + \\
\hline 50 & & + \\
\hline 9. $\mathrm{M} 51^{\circ}$ & NR & \\
\hline 51 & & + \\
\hline 10. $\mathrm{M} 61^{\circ}$ & NR & \\
\hline 61 & & + \\
\hline 11. M26-27* & NR & \\
\hline 26 & & + \\
\hline 27 & & + \\
\hline
\end{tabular}

*Affected males in the same sibship

Affected males in other generations

phenotype. The presence of BTK mutations in 5 of the 6 patients, whose mothers had a random $\mathrm{X}$-chromosome inactivation pattern, suggests that at least $20 \%$ of sporadic cases are due to de novo mutations or to a germinal mosaicism; whereas, an autosomal recessive inheritance of the XLA phenotype can be hypothesized in the sixth patient with no BTK mutation. An interesting outcome of our study is that family history might be directing the diagnostic methodology. Indeed, in all familial cases, where the affected relative was in other generations, $\mathrm{X}$-chromosome inactivation analysis was always informative; whereas, in familial cases with affected males in the same sibship, X-chromosome inactivation was not always informative and BTK gene sequencing was therefore mandatory.

We identified private mutations in 25 out of 29 families. So far, not including the results of this report, about 300 unique molecular events from more than 400 unrelated families have been submitted to the BTKbase (36). Mutations listed in the BTKbase have, in general, an almost even distribution along the BTK sequence, with only a few regions spared. In addition, almost half of the mutations are located in the kinase domain, which comprises $40 \%$ of the total length of BTK. In our population, the distribution of the mutations was also scattered throughout all five structural domains, but definitively favored the kinase domain. This was disproportionately high in the cohort with a familial pattern, where all but 1 of the 9 families had alterations involving the catalytic domain. Although the dimension of the cohort is relatively small, such a high frequency reemphasizes the crucial role played by this catalytic part of the BTK protein. Of the 23 different mutations, including the 9 novel ones, more than half were missense events, which were also highly represented $(78 \%)$ among the novel mutations. A wider spectrum of type of mutations (i.e., missense, deletion and non-sense) affected the $\mathrm{PH}$ domain, with a major clustering in the $\mathrm{N}$-terminal half and the deletion causing a frameshift located in the C-terminal end. So far, all functional mutations have been observed to cluster into the positively charged end of the molecule around the putative binding site for phosphatidylinositol lipids (13). This suggests that $\mathrm{PH}$ mutated residues alter the BTK-dependent B-cell signaling pathway by reducing the affinity for inositol phosphates and, subsequently, a failure in translocation of the kinase to the cell membrane might occur (13). Thus, the identification of specific mutations within each of the functional domains of BTK in XLA patients may serve to define the residues critically involved in BTK-dependent signaling.

B-cell signaling exerts a variety of biologic responses by a complex sequence of events (38). This sequence of events not only provides a signal amplification by combining multiple steps with positive feedbacks, but also allows for recruitment of effectors that 
follow distinct parallel signaling pathways. The demonstration that the very small number of mature B cells $\left(\mathrm{CD}^{-}, \mathrm{CD} 20^{+}, \mathrm{CD} 19^{+}\right.$and $\mathrm{CD} 2 \mathrm{1}^{-}$) present in the peripheral blood of most XLA patients can proliferate, undergo isotype switching and differentiate into specific antibody-producing cells (38) is in accordance with the hypothesis that the maturation signals might be redundant, allowing occasional cells to mature through a separate, parallel pathway. Different mutations within the same gene in single-gene defect diseases result in a range of phenotypes. Accordingly, mutations within BTK were associated with a heterogenous pool of phenotypes, therefore, no phenotype-genotype correlation was observed $(33,36)$. On the contrary, variable phenotypic expression in patients with identical mutations were reported (40). The observation of such a discordancy definitely supports the influence of other genes on BTK regulation. In our study, we could not demonstrate BTK gene mutations in four families, two of which were single sporadic cases and the remaining two both included a pair of siblings. For those familial cases where BTK integrity was observed by NIRCA analysis, cDNA sequence determination was also performed, although with this approach the presence of promoter mutants cannot be excluded. Thus, with all technical restraints, our molecular analysis confirms as a real estimate that $10-20 \%$ of BTK-unaltered patients with an XLA phenotype have disorders caused by different gene defects as previously reported (41). Among the potential candidate genes encoding proteins involved in B-cell signaling that were analyzed in humans, defects in the $m u$ heavy chain gene, $\operatorname{Ig} \alpha$ and $\lambda$ 5/14.1 were demonstrated to be a cause of agammaglobulinemia (23-25).

In conclusion, our findings support $\mathrm{X}$ chromosome inactivation as an informative technique in the counseling of women at risk for being heterozygous for this disorder and as an important adjunct in sporadic cases of XLA. In addition, in the mothers of those affected males with a positive family history in previous sibship, $\mathrm{X}$-chromosome inactivation, by itself, can be considered a reliable and practical diagnostic approach. In all other cases, such as affected males with an XLA phenotype and a sporadic or a familial occurrence in the same generation, BTK gene sequencing is a manda- tory tool for a definitive diagnosis of XLA. Furthermore, our findings contribute to substantiate the notion that XLA phenotype comprises more than one single gene defect. Clearly, in order to provide insights into the precise molecular mechanism of the pathogenesis of XLA we are currently investigating the BTK protein and its functional activity.

\section{Acknowledgments}

Contributing authors of the Italian XLA Collaborative Group include: B. Martire, F. Cardinale, G. Cazzola, D. De Mattia, M. Duse, M. Fiore, S. Martino, M. Masi, V. Monafo, C. Pietrogrande, C. Pignata, I. Quinti, V. Ragno, A. Stabile. We greatly appreciate the cooperation of the many families who were included in this study. We thank prof. L. D. Notarangelo for critically reading the manuscript. This study was supported by Italian Ministry of Health, Grant no. 9701059 (Progetto di Ricerca Finalizzato), Greek Ministry of Development, General Secretariat of Research and Technology (Carrier program, A/A 54), The Swedish Medical Research Council, by Telethon, grant E.668 (A.P., M.F. and P.M.), and by Molecular Medicine Laboratory, Angelo Nocivelli, Pediatrics Department, University of Brescia (A.P., M.F., and P.M.).

\section{References}

1. Sideras P, Smith CI. (1995) Molecular and cellular aspects of $\mathrm{X}$-linked agammaglobulinemia. Adv. Immunol. 59: 135-223.

2. Ochs HD, Smith CI. (1996) X-linked agammaglobulinemia. A clinical and molecular analysis. Medicine 75: 287-299.

3. Kwan S-P, Kunkel L, Bruns G, Wedgwood RJ, Latt S, Rosen FS. (1986) Mapping of the Xlinked agammaglobulinemia locus by use of restriction fragment-length polymorphism. J. Clin. Invest. 77: 649-52.

4. Guioli S, Arveiler B, Bardoni B, et al. (1989) Close linkage of probe p212 (Dxs178) to Xlinked agammaglobulinemia. Hum. Gen. 84: 12-21.

5. Tsukada S, Saffran DC, Rawlings DJ, et al. (1993) Deficient expression of a B cell cytoplasmic tyrosine kinase in human X-linked agammaglobulinemia. Cell 72: 279-290.

6. Vetrie D, Vorechovski I, Sideras P, et al. (1993) The gene ivolved in $\mathrm{X}$-linked agammaglobulinemia is a member of the src family of protein tyrosine kinases. Nature 361: 226-233. 
7. Sideras P, Muller S, Shiels H, et al. (1994) Genomic organization of mouse and human Bruton's agammaglobulinemia tyrosine kinase (BTK) loci. J. Immunol. 153: 5607-5617.

8. Vihinen M, Nilsson L, Smith CIE. (1994) Tec homology $(\mathrm{TH})$ adjacent to the $\mathrm{PH}$ domain. FEBS Lett. 350: 263-265.

9. Desiderio S. (1997) Role of BTK in B cell development and signaling. Curr. Opin. Immunol. 9: 534-540.

10. Satterwaithe AB, Li Z, Witte ON. (1998) BTK function in B-cell development and response. Semin. Immunol. 10: 309-316.

11. Ma YC, Huang XY. (1998) Identification of the binding site for $\mathrm{G}_{\mathrm{q}} \alpha$ on its effector Bruton's tyrosine kinase. Proc. Natl. Acad. Sci. U.S.A. 95: 12197-12201.

12. Bence K, Ma W, Kozasa T, Huang XY. (1997) Direct stimulation of Bruton's tyrosine kinase by G(q)-protein $\alpha$ subunit. Nature 389: 296-299.

13. Hyvonen M, Saraste M. (1997) Structure of the PH domain and BTK motif from Bruton's tyrosine kinase: molecular explanations for XLA. EMBO J. 16: 3396-3404.

14. Saha BK, Curtis SK, Vogler LB, Vihinen M. (1997) Molecular and structural characterization of 5 novel mutations in the BTK gene from patients with XLA. Mol. Med. 3: 477-485.

15. Bolland S, Pearse RN, Kurosaki T, Ravatch JV. (1999) SHIP modulates immune receptor responses by regulating membrane association of BTK. Immunity 8: 509-516.

16. Salim K, Bottomley MJ, Querfurth E, et al. (1996) Distinct specificity in the recognition of phosphoinositides by the pleckstrin homology domains of dynamin and Bruton's tyrosine kinase. EMBO J. 15: 6241-6250.

17. Fruman DA, Snapper SB, Yball CM, et al. (1999) Impaired B-cell development and proliferation in absence of phosphoinositide 3-kinase p85 $\alpha$. Science 283: 393-397.

18. Suzuki H, Terauchi Y, Fujiwara M, et al. (1999) Xid-like immunodeficiency in mice with disruption of the p85 $\alpha$ subunit of phosphoinositide 3-kinase. Science 283: 390-392.

19. WHO Scientific Group. (1995) Primary immunodeficiency diseases. Clin. Exp. Immunol. 99(suppl 1): 1-24.

20. Lederman HM, Winkelstein JA. (1985) Xlinked agammaglobulinemia: an analysis of 96 patients. Medicine 64: 145-156.

21. Hoffman T, Winchester R, Schulkind M, Frias JL, Ayoub EM, Good RA. (1977) Hypoimmunoglobulinemia with normal $\mathrm{T}$-cell function in female siblings. Clin. Immunol. Immunopathol. 7: 364-371.

22. Conley ME, Sweinberg SK. (1992) Females with a disorder phenotypically identical to XLA. J. Clin. Immunol. 12: 139-143.
23. Minegishi $\mathrm{Y}$, Coustan-Smith E, Wang Y-H, Cooper MD, Campana D, Conley ME. (1998) Mutations in the human $\lambda$ 5/14.1 gene result in B-cell deficiency and agammaglobulinemia. J. Exp. Med. 187: 71-77.

24. Yel L, Minegishi Y, Coustan-Smith E, et al. (1998) Mutations in the mu heavy chain gene in patients with agammaglobulinemia. N. Engl. J. Med. 335: 1486-1493.

25. Minegishi Y, Coustan-Smith E, Rapalus, et al. (1999) An essential role for Ig $\alpha$ in B-cell development. In: B lymphocyte biology and disease. Keystone Symposia. p. 76.

26. Conley ME, Brown P, Pickard AR, et al. (1986) Expression of the gene defect in X-linked agammaglobulinemia. N. Engl. J. Med. 315: 564-567.

27. Conley ME, Puck JM. (1988) Carrier detection in typical and atypical XLA. J. Pediatr. 112: 688-694.

28. Fearon ER, Winkelstein JA, Livin CS, Pardoll DM, Vogelstein B. (1987) Carrier detection in $\mathrm{X}$-linked agammaglobulinemia by analysis of X-chromosome inactivation. N. Engl. J. Med. 316: 427-431.

29. Allen RC, Nachtman RC, Rosenblatt HM, Belmont JW. (1994) Application of carrier testing to genetic counseling for X-linked agammaglobulinemia. Am. J. Hum. Genet. 54: 25-35.

30. Goldrich MM, Kimball GR, Liu Q, Martin LA, Sommer SS, Tseng JY-H. (1996) NIRCA: a rapid robust method for screening for unknown point mutations. Biotechniques 21: 106-112.

31. Ritis K, Speletas M, Tsironidou V, et al. (1998) Absence of BTK mutations in patients with acute myeloid leukemia. Br. J. Hematol. 102: 1241-1248.

32. Hultman T, Stahl S, Homes E, Uhlen M. (1989) Direct solid phase sequencing of genomic and plasmid DNA using magnetic beads as solid support. Nucleic Acid Res. 17: 4937-4946.

33. Holinski-Feder E, Weiss M, Brandan O, et al. (1998) Mutation screening of the BTK gene in 56 families with XLA: 47 unique mutations without correlation to clinical course. Pediatrics 101: 276-284.

34. Wicker LS, Scher I. (1986) X-linked immune deficiency (xid) of CBA/N mice. Curr. Top. Microbiol. Immunol. 124: 87-101.

35. Vorechovsky I, Luo L, Hertz JM, et al. (1997) Mutation pattern in the BTK gene in 26 unrelated patients with XLA. Hum. Mut. 9: 418-425.

36. Vihinen M, Kwan SP, Lesten T, et al. (1999) Mutations of the human BTK gene coding for BTK in X-linked agammaglobulinemia. Hum. Mut. 13: 280-285.

37. Vihinen M, et al. (1996) BTKbase: XLA mutation registry. Immunol. Today 17: 502-506.

38. Benschop RJ, Cambier JC. (1999) B-cell devel- 
opment: signal transduction by antigen receptors and their surrogates. Curr. Op. Immunol. 11: 143-151.

39. Nonoyama S, Tsukada S, Yamadori T, et al. (1998) Functional analysis of peripheral blood B-cells in patients with X-linked agammaglobulinemia. J. Immunol. 161: 3925-3929.
40. Bykowski MJ, Haire RN, Ohta Y, et al. (1996) Discordant phenotype in siblings with XLA. Am. J. Hum. Genet. 58: 477-483.

41. Conley ME, Mathias D, Treadaway J, Minegishi Y, Rohrer J. (1998) Mutations in BTK in patients with presumed X-linked agammaglobulinemia. Am. J. Hum. Genet. 62: 1034-1043. 